\title{
Coal-Bearing Zone Transformation into a Coalless One at the Open Pit
}

\author{
Oleg Litvin ${ }^{1}$, Ekaterina Tyuleneva ${ }^{1}{ }^{*}$, Valery Kolesnikov ${ }^{1}$, and Alexandr Dobrov ${ }^{1}$ \\ ${ }^{1}$ T.F. Gorbachev Kuzbass State Technical University, 650000, 28 Vesennyaya street, Kemerovo, \\ Russia
}

\begin{abstract}
Currently, two types of handling machines are mainly used on coal open pit mines in Kuzbass, characterized by complex structural deposits: mechanical (rope) and hydraulic (backhoe) shovels. Moreover, both types of equipment are supplied to the quarries: mechanical shovels are purchased, as a rule, powerful with a bucket capacity up to $56 \mathrm{~m}^{3}$, backhoes - small and medium-size models with a bucket capacity of 2.8$14 \mathrm{~m}^{3}$. On the other hand, it is common to divide the areas of equipment use in the open pit on complex-structured deposits into a coalless (outside the strata of coalbeds) and coal-bearing (actually a series of beds, including coal strata and rock interbeds). The use of these equipment types in both design and industrial practice is observed in both zones. At the same time, it is known that each of these zones has different conditions for the efficient operation of excavation machines. The seams, therefore, do not complicate the coalless zone when working in it, favorable conditions are provided for the excavator: the constant height of the bench, which is necessary for the full filling of the bucket for one scoop, the constant width of the panel and the length of the front of the work. In these conditions, the maximum productivity of the excavator is ensured.
\end{abstract}

\section{Introduction}

The mining of the coal-bearing zone is complicated by the need to extract coal seams with the requirement of a minimum level of coal losses. In this zone, it is also necessary to excavate an overburden rock along parting (interbeds), whose thickness varies widely from several meters to $100-140 \mathrm{~m}$. Thus, in this zone the use of excavators requires, for their effective use, have a number of special technological features [1-3].

These differences in the conditions of the development of zones pose the question of the rational use of excavator types in them. In the technical literature on this subject, there is a discussion that boils down to a dilemma: rope or hydraulics?

The advantages and disadvantages of rope mechanical shovels and backhoes are considered, both from the point of view of productivity $[2,4]$, conditions of exploitation [1, $5,8-9]$, maintainability [7], durability, economics [8, 13], and from the point of view of technological features of mining $[6,10-11]$. It is noted that mechanical shovels are more

\footnotetext{
*Corresponding author: tyulenevaea@kuzstu.ru
} 
productive than backhoes with the same bucket capacity, are more repairable, more durable. In operation, they are cheaper (because lower operating costs). Disadvantages: heavy and not maneuverable enough; having higher level of coal losses; the need to switch the cable; sensitivity to changing the height of the bench, which affects the duration of the working cycle $[1,8]$.

Backhoes have the follows advantages: lighter (in comparison with rope shovels with same bucket capacity), autonomous, maneuverable. A selective opportunity to work out the faces, allowing selective excavation of individual face elements. Disadvantages: poor maintainability, fragility, substantially higher operating costs.

But the combination of the above factors cannot yet serve as a basis for recommendations on the rational application of the types of excavating machines; however, it is necessary to consider these factors when formulating recommendations.

Also, there are no studies in the literature aimed at finding technological solutions for the development of complex-structure coal deposits, which take into account the application of both types of handling equipment, with the maximum use of their advantages. Therefore, studies on such issues are relevant.

The foregoing allows us to formulate the research goal. It is to substantiate the technology for the development of complex structure coal deposits with the use of different types of mining equipment in the quarry field with different geological structure that will improve the efficiency of open pit mining. The idea of the job is to provide the conditions for the achievement of shovels with maximum productivity, for which it is proposed to carry out anticipatory development of coal seams and tectonic dislocations.

In this paper, the technology for the development of a coal-bearing zone is considered. The essence of this one is the preliminary excavation in the coal-bearing zone of only coal seams, and excavation of interbeds will be carried out by rope shovel. We called this technology "the technology of transformation the coal-bearing zone to a coalless one".

\section{Materials \& Methods}

The excavating-and-loading operations are the second after the preparation of rocks [14, 15] for excavation by the open-cast mining process. The specific weight of the costs of mentioned above operations in total costs per unit volume of rock mass for transport technology, depending on the properties of the rocks, ranges from 15 to $40 \%$ [12]. The main types of excavating machines used in quarries are single-bucket and multi-bucket excavators; one-bucket loaders; machines for the non-explosive excavation of semi-rock and rock; scrapers; bulldozers.

In accordance with the development projects of deposits made in the 50-70s of the 20th century, the handling of excavation and loading operations on the open pits of Kuzbass was carried out by rope electric shovels. Since the mid-1990s, due to the development of outer trade, foreign mining equipment began to arrive at the Kuzbass open pits - first of all, hydraulic shovels and backhoes.

The handling of excavating-and-loading operations in the zone of inclined coal seams becomes more complicated due to the limitation of the height of the bench by the height of the scooping of the "rock-and-coal" contact both by rope and hydraulic excavators.

In recent years, the excavator park of the Kuzbass open pit enterprises has been replenished mainly due to backhoes. However, the expediency of their application in some cases is not justified.

Wide range of possible trajectories of the bucket movement of hydraulic excavators provides a high efficiency of their application in the development of complex-structure deposits, where a clear separation of minerals and rocks is required when they are excavated. Also, hydraulic excavators are characterized by higher reliability. 
Foreign hydraulic excavators are produced both with electric and diesel drive, which provides them with high mobility and independence from the energy source. They are distinguished by high marks both in performance and reliability in operation. But maintaining their high operational conditions after 5-7 years of operation is associated with very high costs, in connection with which the excavation and loading of the rock is more expensive than with the use of domestic excavators of the ECG type (Russian rope shovels).

\section{Results \& Discussion}

In Kuzbass, at almost every open pit, from 3 to 17 coal seams are in development. Moreover, the developed strata have different thickness with angles of incidence from $3^{\circ}$ to $90^{\circ}$. In addition, there are a number of plicate and disjunctive dislocations (Figure 1, 2).

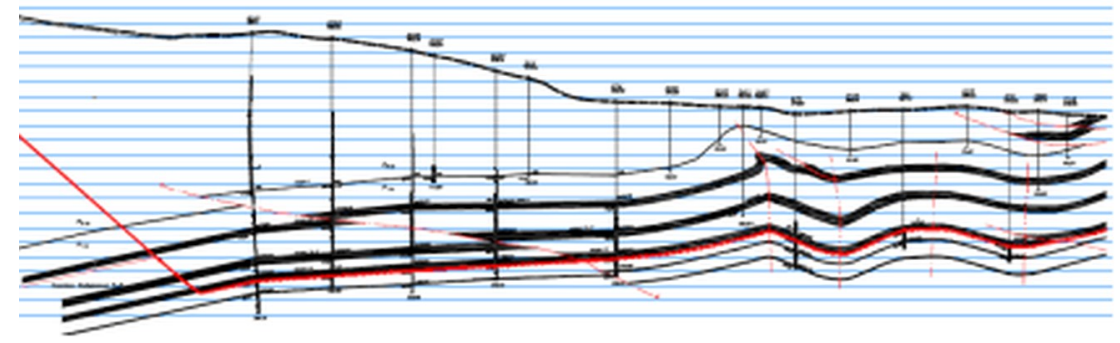

Fig. 1. Typical geological section (open pit mine Mezhdurechensky)

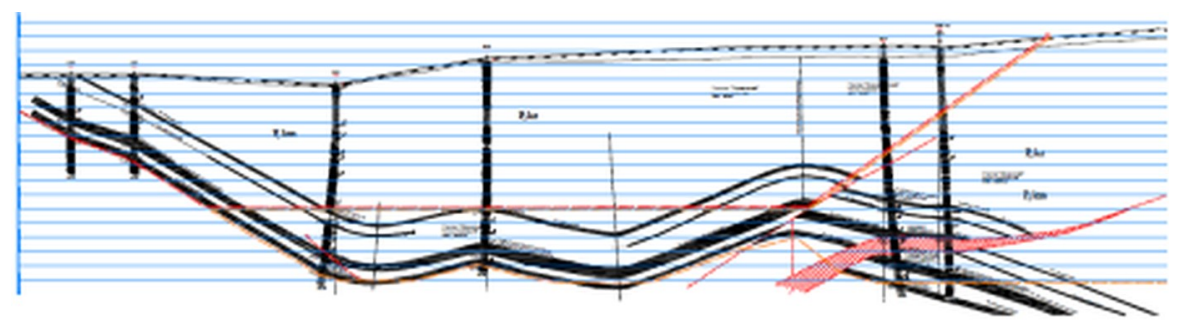

Fig. 2. Typical geological section (open pit mine Chernigovsky)

In such conditions, mining is seriously complicated, and losses and dilution of minerals sharply increase. Particularly difficult is the excavation of thin seams $(<5 \mathrm{~m})$, whose share in the total production in the Kuzbass reaches $15-17 \%$, and the level of losses in some cases is $35-40 \%$ and more. And it is low-thickness strata are usually represented by the most high-quality energy and coking coals. Therefore (especially in the coal-bearing zones of the open pits), a selective excavation is used to reduce losses and impoverishment of the mineral. The methods and schemes for excavating the rock and minerals in the process of working out such dips are selected each time in accordance with their structure. The simplest implementation of a selective excavation is with the consonant (in relation to the slope of the bench) occurrence, or when the rock and mineral zones along the length of the stope are clearly divided into separate homogeneous blocks.

The experience of Kuzbass open pit mining shows the feature: when coal excavating in coal-bearing zones, including low-thickness seams, it is advisable to use excavators with a bucket capacity of no more than 4-5 $\mathrm{m}^{3}$. Increasing the bucket capacity to $8 \mathrm{~m}^{3}$, and even more so to $10-12.5 \mathrm{~m}^{3}$ leads to a sharp increase in coal losses, which can reach $40-55 \%$.

Separate excavation is inevitably connected with the loss of productivity of excavators and transport units, which means an increase in the cost of mining. 
Separate excavation using rope electric excavators can significantly reduce losses of minerals, but cannot exclude them completely. Losses and impoverishment occur during blasting operations, during stripping and excavation of seams and deposits due to the mismatch of the trajectory of the excavator bucket movement with the contact plane of the rock-mineral, and also during loading. The use of hydraulic excavators is particularly effective for selective excavation of complex structural faces, as they allow to choose the trajectory of the bucket motion, providing a clear scoop across the rock-minerals contact. At the same time, losses and impoverishment of minerals are significantly reduced, and the productivity of excavators is increased in comparison with mechanical shovels. The technology for the development of open pit fields in the Kuzbass open pits with inclined and steep bedding implies the development of a coalless zone with hydraulic shovels or backhoes with benches of normal height.

The direction of moving the work front to the coal-bearing zone, as a rule, occurs from the side of the roof of the upper bed of the strata (Fig. 3). In the coal-bearing zone, the use of backhoes for the excavation of coal seams is supposed to ensure minimum losses of coal.

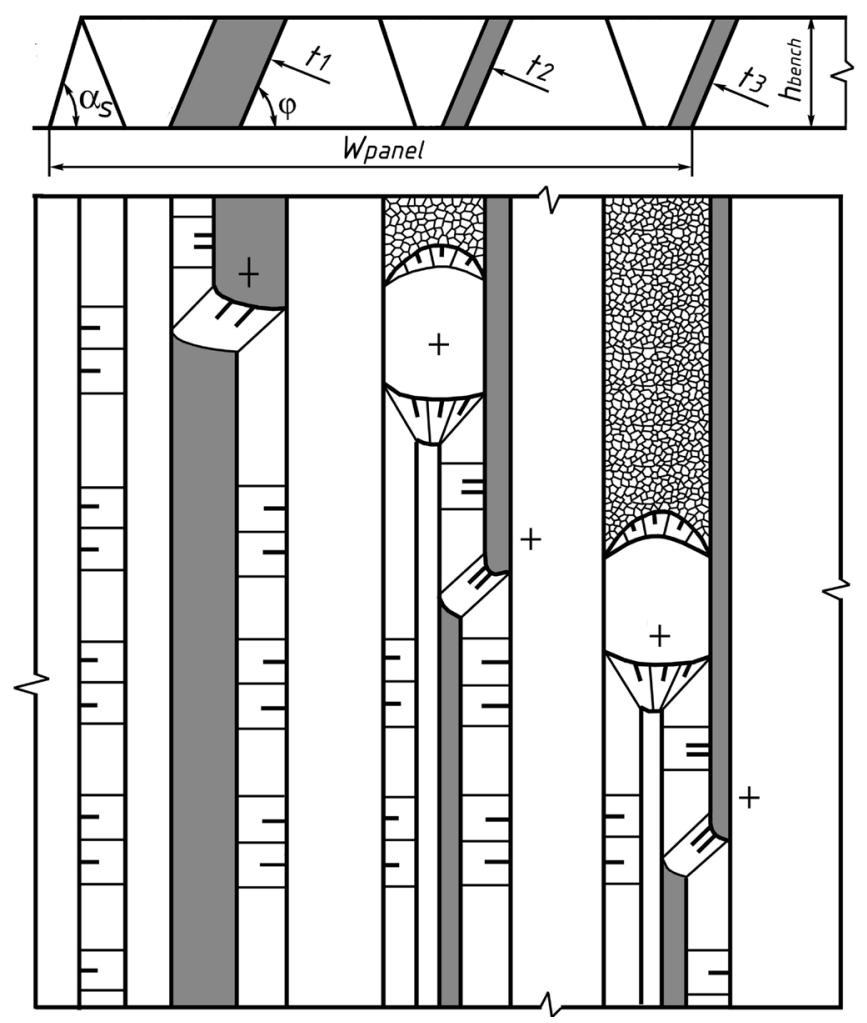

Fig. 3. The schematic diagram of the technology for the development of the coal-bearing zone by wide panels with preliminary excavation of coal seams

The need for separate seam extraction pushes rigid requirements for the technological scheme: the excavation must be carry out from the side of the formation's roof with the mining of the split trench, and the insertion into the interbed should not be accompanied by a cutting of the overlying horizon (Fig. 4).

In accordance with these requirements, the mutual position of the coal beds in the coalbearing zone may be isolated (dispersed) or closed. 
To evaluate the closeness, a criterion $I_{\min }^{\text {close }}$ is calculated for the backhoe to work out the coal bed without cutting the adjacent one (Figure 4):

$$
I_{\min }^{\text {close }}=\frac{H_{b}}{\sin \alpha_{s}} \cdot \sin \left(\alpha_{s}+\varphi\right)+W_{b} \cdot \sin \varphi .
$$

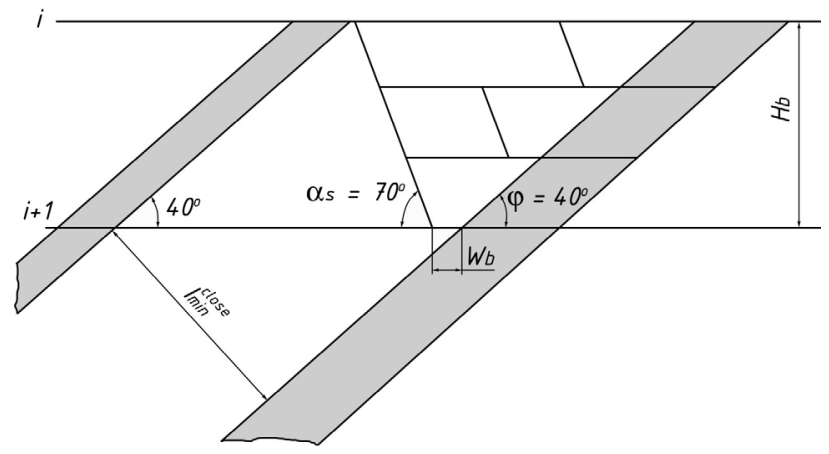

Fig. 4. Scheme to determine the closeness of inclined and steep coal seams

On the Fig. 3 and 4: $\mathrm{H}_{\mathrm{b}}\left(\mathrm{H}_{\text {bench }}\right)$ - the height of a bench; $\mathrm{W}_{\mathrm{b}}$ - width of backhoe's bucket (minimum width of a cutting trench); $\alpha_{\mathrm{s}}$ - slope angle; $\varphi$ - angle of coal bed inclination; $\mathrm{t}_{1}$, $t_{2}, t_{3}-$ thickness of $1^{\text {st }}, 2^{\text {nd }}$ and $3^{\text {rd }}$ coal beds consequently; $W_{\text {panel }}-$ width of coal-and-rock panel.

If the normal thickness of the parting $I_{\text {normal }} \geq I_{\mathrm{min}}^{\text {close }}$, then the coal beds are dispersed; if $I_{\text {normal }}<I_{\min }^{\text {close }}$, the coal beds are near-by and their development should be carry out jointly by a multilayer technological scheme.

\section{Conclusions}

The long experience of using hydraulic excavators in Kuzbass quarries has shown that after several years of operation, they largely lose some of their advantages in comparison with domestic-made electric shovels. Their productivity and economic expediency of further use are significantly reduced. This is due to the fact that with the increase in service life, their idle time increases due to failures in the nodes of the hydraulic system and the mechanical part. Restoration of excavators is extremely hampered by the lack of spare parts and an obvious shortage of a complex repair base for this kind of equipment at mining enterprises.

With an increase in the life of hydraulic excavators up to 6-7 years, the rate of decline in their productivity is much higher than that of electric rope excavators. During the first years of operation, the productivity of hydraulic excavators is $1.3-1.5$ times higher than in the mechanical shovels, and after 6-7 years, this difference is only $10-15 \%$.

Thus, for effective use of mechanic shovels and hydraulic backhoes, it is necessary to determine their "working zone", taking into account the strengths and weaknesses of each type of excavator. With the compliance of a number of technological features, the maximum productivity of the excavator will be ensured. So we can conclude the following:

1. For separate coal extraction, the use of backhoes is most preferable. Schemes of excavation are very diverse $[2,8,16]$ and are chosen applied to the specific structure of the face. 
2. With the selective development of inclined coal strata, it is possible to use both shovels and backhoes. In both cases, the bench of normal height should be divided into subbenches.

3. With the selective excavation of flat seams, including rock interbeds, hydraulic backhoe excavators layer-by-layer work on coal packs and rock interbeds. As a result, it is possible to significantly reduce the impoverishment and loss of coal in comparison with the bulk mining.

\section{References}

1. M.A. Tyulenev, S.A. Zhironkin, O.I. Litvin, E.A. Tyuleneva, O.V. Zhironkina, S.O. Markov, Geotech. Geol. Eng. 35(5), 2065 (2017)

2. M. Tyulenev, S. Zhironkin, E. Tyuleneva, A. Abay, S. Anyona, M. Hellmer, Coal Int., 265(3), 30 (2017)

3. M.A. Tyulenev, T.N. Gvozdkova, S.A. Zhironkin, E.A. Garina, Geotech. Geol. Eng., 35(1), 203 (2017)

4. T. Gvozdkova, E. Kuznetsov, A. Rudakova, S. Markov, E3S Web of Conf., 15, 01008 (2017)

5. S. Markov, M. Tyulenev, O. Litvin, E. Tyuleneva, E3S Web of Conf., 15, 01011 (2017)

6. M. Tyulenev, E. Garina, A. Khoreshok, O. Litvin, Y. Litvin, E. Maliukhina, IOP Conf. Ser.: Earth Environ. Sci., 50(1), 012035 (2017)

7. A. Kvasova, B. Gerike, E. Murko and D. Skudarnov, E3S Web Conf., 21, 03016 (2017)

8. O. Litvin, M. Tyulenev, S. Zhironkin, S. Prokopenko, Acta Montanistica Slovaca, 22(2), 500 (2017)

9. M. Tyulenev, Y. Lesin, O. Litvin, E. Maliukhina and A. Abay, E3S Web Conf., 21, 02019 (2017)

10. T. Gvozdkova, S. Markov, N. Demirel and S. Anyona, E3S Web Conf., 21, 01024 (2017)

11. S. Markov, V. Martyanov, E. Preis and A. Abay, E3S Web Conf., 21, 01021 (2017)

12. M. Tyulenev, Y. Lesin, E. Tyuleneva, E. Murko, E3S Web Conf., 15, 02003 (2017)

13. A. Verzhanskij. Y. Dmitrak, Ugol', 6, 2005

14. V.A. Gogolin, Y.A. Ryzhkov, Soviet Mining Science, 17, 156 (1981)

15. V.A. Gogolin, Y.A. Ryzhkov, Soviet Mining Science, 13, 17 (1977)

16. V. Kolesnikov, O. Litvin, J. Janočko and A. Efremenkov, E3S Web Conf., 21, 01031 (2017) 